\title{
Capstone Design Kapal Tanpa Awak sebagai Media Survei Tingkat Kualitas Air di Suatu Perairan
}

\author{
Muh Hisyam Khoirudin dan Wasis Dwi Aryawan \\ Departemen Teknik Perkapalan, Fakultas Teknologi Kelautan, \\ Institut Teknologi Sepuluh Nopember (ITS) \\ e-mail:wasis@na.its.ac.id
}

\begin{abstract}
Abstrak-Pencemaran terhadap air saat ini terus menerus terjadi. Mayoritas mutu air sungai maupun laut yang ada di teritori negara Indonesia sudah dalam status tercemar berat. Oleh karena itu, dibutuhkan alat sebagai media survei kualitas air tersebut dalam rangka pengendalian limbah yang masuk ke wilayah penampungan air secara lebih komprehensif. Model kapal tanpa awak yang dilengkapi dengan sistem autopilot dan sensor (sensor suhu, konduktivitas, dan PH) merupakan solusi yang dapat digunakan sebagai media survei kualitas air. Dengan sistem autopilot berdasarkan sensor GPS dan sensor ultrasonik, model tersebut mampu menyusuri perairan dengan medan yang sulit dijangkau manusia serta mampu menghindari halangan yang ada di depannya. Ketika lokasi telah ditentukan, model kapal tanpa awak akan bergerak secara otomatis dan sistem akusisi data sensor akan mengukur suhu, konduktivitas, dan tingkat keasaman yang ada di sekitar lokasi kapal secara waktu-nyata. Hasil pengukuran data tersebut langsung dikirimkan ke pengguna melalui wireless serial module. Hasil pengujian sistem ini menunjukkan bahwa model kapal tanpa awak mampu bergerak secara otomatis maupun manual untuk pengambilan data. Pada pengukuran data sensor suhu memiliki kesalahan maksimal 3.1\%, data sensor konduktivitas memiliki maksimal kesalahan $5.2 \%$, sedangkan pada pengukuran data sensor PH memiliki kesalahan maksimal $2.9 \%$. Sistem model kapal tanpa awak ini mampu memantau dan mensurvei tingkat kualitas air secara otomatis sehingga dapat digunakan untuk membantu manusia dalam hal pengendalian mutu air di perairan tertentu.
\end{abstract}

Kata Kunci-Kapal tanpa awak, Sistem autopilot, Menghindar, dan Sistem akusisi data sensor.

\section{PENDAHULUAN}

A IR adalah senyawa penting bagi semua bentuk kehidupan manusia maupun makhluk hidup lainnya. Karena penting, air perlu dijaga kualitasnya agar dapat digunakan untuk keperluan sehari-hari dan terjaga kestabilan ekosistem di dalamnya. Namun, yang terjadi saat ini pencemaran terhadap air terus menerus terjadi. Menurut Peraturan Pemerintah No. 82 Tahun 2001 pencemaran air adalah masuknya atau dimasukkannya makhluk hidup, zat, energi, dan atau komponen lain ke dalam air oleh kegiatan manusia, sehingga kualitas air turun sampai ke tingkat tertentu yang menyebabkan air tidak dapat berfungsi sesuai dengan peruntukannya.

Sumber pencemaran air dapat berasal dari limbah, baik limbah industri maupun limbah rumah tangga. Kategori air tercemar atau tidak tercemar tergantung dari status mutu air yang dibandingkan dengan nilai baku mutu air. Aspek-aspek yang terdapat pada nilai baku mutu air dapat berupa aspek fisik maupun kimia. Beberapa aspek tersebut antara lain adalah tingkat keasaman $(\mathrm{PH})$, suhu, dan konduktivitas.

Berdasarkan laporan yang dikeluarkan oleh Direktorat Jenderal Pengendalian Pencemaran dan Kerusakan Lingkungan Kementerian Lingkungan Hidup dan Kehutanan (KLHK), di tahun 2015 hampir 68 persen atau mayoritas mutu air sungai di 33 provinsi di Indonesia dalam status tercemar berat. Hal ini juga diperkuat oleh hal yang diungkapkan oleh Kasi Pengendalian Pencemaran Air Rumah Tangga Direktorat Jenderal Pengendalian Pencemaran dan Kerusakan Lingkungan, Kementerian KLHK berupa "Kontribusi limbah domestik di air sungai di atas 60 persen. Kondisi itu harus ditanggapi dan diatasi serius."

Untuk mengatasi pencemaran tersebut, maka dibutuhkan pengendalian limbah yang masuk ke daerah penampungan air secara lebih komprehensif. Dan dalam rangka pengendalian limbah ini, perlu dilakukan kegiatan survei dengan tujuan memonitoring tingkat kualitas air pada suatu daerah perairan. Dengan adanya monitoring tersebut, data-data yang diperoleh dapat dijadikan acuan untuk menyimpulkan kondisi perairan tersebut tercemar maupun tidak tercemar.

Metode yang umumnya dilakukan oleh para peneliti untuk melakukan survei tingkat kualitas air adalah dengan mengambil sampel langsung di perairan tersebut untuk kemudian diuji di laboratorium. Metode tersebut akan sangat menyulitkan ketika sampel air yang diinginkan lokasinya jauh dengan peneliti. Sehingga, diperlukan kapal tanpa awak dengan kendali pilot maupun autopilot (otomatis) untuk menjangkau daerah yang tidak bisa dijangkau peneliti dan melakukan kegiatan survei untuk mendata kualitas air di daerah tersebut.

Kendali autopilot merupakan hal yang sangat lumrah di era teknologi dan komunikasi yang semakin berkembang ini. Tugas manusia semakin terbantu dengan hadirnya teknologi berupa robot. Teknologi ini sudah mulai masuk pada dunia transportasi yang salah satunya adalah kapal tanpa awak. Dengan adanya teknologi robot atau kendali otomatis pada kapal tanpa awak, maka kapal tersebut diharapkan dapat membantu bahkan menggantikan tugas manusia dalam melakukan tugasnya.

Kapal tanpa awak akan dilengkapi oleh sensor tingkat keasaman, sensor suhu, dan sensor konduktivitas untuk mendeteksi kualitas air dari suatu perairan. Sensor GPS, sensor kompas, dan sensor ultrasonik pun juga digunakan sebagai perangkat navigasi agar kapal dapat dikendalikan secara otomatis. Hasil dari pengukuran kualitas air tersebut akan ditampilkan dengan Graphic User Interface (GUI) untuk memudahkan pengguna dalam melihat informasi hasil survei tersebut. 


\section{TINJAUAN PUSTAKA}

\section{A. Kapal Tanpa Awak}

Istilah Unmanned Surface Vehicle (USV) atau Autonomous Surface Vehicle (ASV) atau Kapal Tanpa Awak dimaksudkan untuk wahana yang dioperasikan pada permukaan air tanpa awak. USV dikendalikan autopilot dengan memberikan perintah- perintah seperti waypoint, melalui Ground Control Station (GCS). USV dapat mengolah data-data pergerakan dan pengamatan lalu mengirimkannya ke GCS secara real time melalui sistem komunikasi nirkabel [1].

Dengan ukurannya yang kecil, maka USV akan mudah dimobilisasi menggunakan kapal konvensional yang lebih besar. Kemudian USV akan disebar ke berbagai titik untuk melakukan patroli di wilayah yang telah ditetapkan sesuai koordinat GPS yang telah ditetapkan. Namun, saat ini penggunaan USV tidak terbatas pada kegiatan patroli, melainkan kegiatan apa saja yang dapat membantu kegiatan manusia seperti kegiatan survei. Dengan adanya USV, campur tangan manusia dapat diminimalkan sehingga dapat memperkecil resiko yang diterima surveyor ketika melakukan kegiatan survei di area perairan berbahaya.

\section{B. Sistem Kontrol}

Pengertian sistem kontrol adalah proses pengaturan atau pengendalian terhadap satu atau beberapa besaran (variabel, parameter) sehingga berada pada suatu harga atau dalam suatu rangkuman harga (range) tertentu. Sedangkan, aksi kontrol yang paling umum digunakan di dunia adalah kontrol Proportional, Integral, Derivative (PID). Aksi kontrol PID merupakan suatu kontroler yang berfungsi untuk menentukan kepresisian (kestabilan) suatu sistem instrumentasi dengan karakteristik umpan balik pada sistem tersebut.

Aksi kontrol PID banyak ditemukan di dunia industri dan satu-satunya strategi yang paling banyak diadopsi pada pengontrolan proses. Berdasarkan survei, $97 \%$ industri yang bergerak dalam bidang proses (seperti kimia, pulp, makanan, minyak, dan gas) menggunakan PID sebagai komponen utama dalam pengontrolannya [2].

Kontroler PID terdiri dari tiga parameter yaitu $\mathrm{P}$ (proportional), D (derivative), I (integral). Sebuah kontroler PID secara kontinyu menghitung nilai kesalahan sebagai beda antara set point yang diinginkan dan variabel proses terukur. Kontroler mencoba untuk meminimalkan nilai kesalahan setiap waktu dengan penyetelan variabel kontrol ke nilai baru. Masing-masing aksi kontrol ini mempunyai keunggulankeunggulan tertentu, dimana aksi kontrol proporsional mempunyai keunggulan rise time yang cepat, aksi kontrol integral mempunyai keunggulan untuk memperkecil error, dan aksi kontrol derivative mempunyai keunggulan untuk memperkecil error atau meredam overshot/undershot. Untuk itu agar kita dapat menghasilkan output dengan rise time yang cepat dan error yang kecil kita dapat menggabungkan ketiga aksi kontrol ini menjadi aksi kontrol PID [3].

\section{Sistem Navigasi}

Navigasi adalah ilmu pengetahuan dalam menentukan posisi kapal di perairan dengan mengemudikan (steering) kapal secara aman dari suatu tempat ke tempat lain. Sistem navigasi biasanya terdiri dari beberapa perangkat digital maupun analog, untuk yang analog biasanya dilengkapi dengan kompas analog yang dapat mengetahui arah mata angin yang berguna sebagai acuan arah kapal, untuk perangkat digital sudah terdapat GPS atau Global Positioning
System yaitu sebuah perangkat yang dapat menerima lokasi keberadaan kapal dengan mengacu pada satelit yang bergerak mengitari bumi. GPS menerima data yang dikirim dari satelit berupa data NMEA 0183. NMEA (National Marine Electronics Association) adalah standar yang digunakan dalam pengiriman data GPS yang berupa protokol data, garis lintang, garis bujur, ketinggian, dan waktu. Kompas digital juga tergolong perangkat digital dimana pemakaiannya harus diintegrasikan kembali pada sebuah sistem sehingga pembacaan arah mata angin dapat dilakukan dan dapat mengetahui arah kapal [4].

\section{METODOLOGI PENELITIAN}

Tahapan dari metodologi penelitian dapat dilihat pada diagram alir pada Gambar 1.

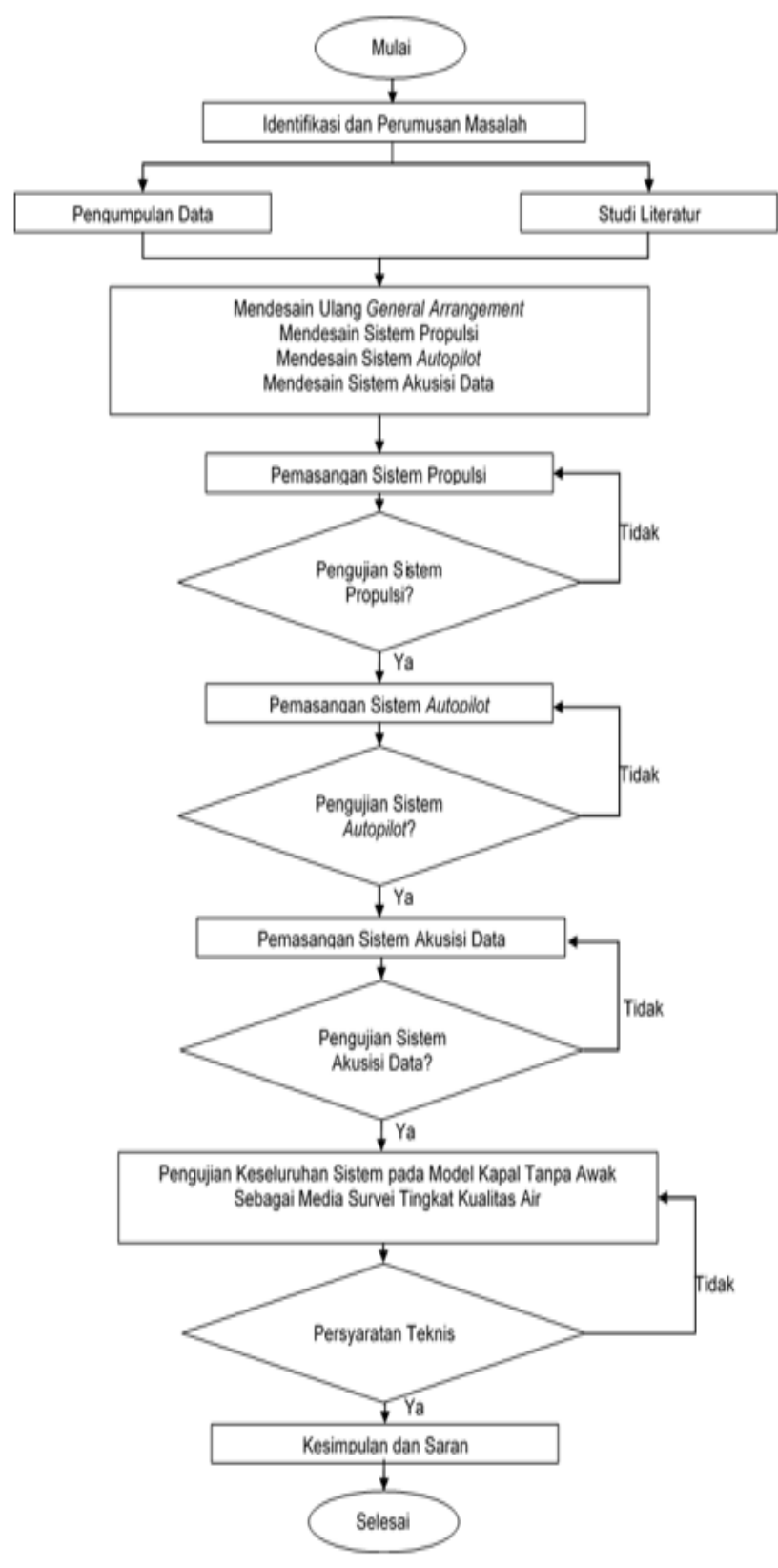

Gambar 1. Diagram alir.

\section{DESAIN DAN PEMBUATAN}

\section{A. Pembuatan General Arrangement Baru}

Proses pembuatan general arrangement baru dari model kapal tanpa awak didasarkan atas kebutuhan sistem di dalam 
model kapal tanpa awak yang berbeda dari desain sebelumnya. Kebutuhan sistem yang berbeda tersebut terdiri dari bagian-bagian sistem propulsi, sistem autopilot, dan sistem akusisi data sensor. General arrangement ini dibuat berdasarkan bentuk model dari Tugas Akhir Dwiko Hardianto yang berjudul "Pembuatan Konsep Desain Unmanned Surface Vehicle untuk Monitoring Wilayah Perairan Indonesia", Fajar Ramadhan yang berjudul "Pembuatan Detail Desain Unmanned Surface Vehicle untuk Monitoring Wilayah Perairan Indonesia", dan Ericza Damaranda yang berjudul "Pembuatan Purwarupa Tes Model untuk Penguji Sistem Autopilot pada Unmanned Surface Vehicle (USV)".[5], [6]

Data model kapal tanpa awak yang digunakan merupakan skala kecil dari Konsep Desain Unmanned Surface Vehicle yang memiliki panjang (LWL) $6.9 \mathrm{~m}$. Lambung yang digunakan pada model kapal berjenis asymmetric catamaran, yaitu jenis catamaran dengan lambung yang tidak sama simetris antara bentuk keduanya. Dimensi dari model kapal tersebut adalah:

- Panjang (LWL) : $98.60 \mathrm{~cm}$

- Tinggi $(\mathrm{H}) \quad: 18.10 \mathrm{~cm}$

- $\operatorname{Lebar}(\mathrm{B}) \quad: 51.40 \mathrm{~cm}$

- Sarat (T) : $7.00 \mathrm{~cm}$

- Displacement : $9.78 \mathrm{~kg}$

Pembuatan general arrangement yang baru dimulai dari memeriksa layout dari model kapal tanpa awak. Layout yang paling dibutuhkan adalah pada bagian main deck, karena mayoritas dari komponen sistem yang ada di atas model akan diletakkan pada bagian tersebut. Dari kebutuhan sistem, selanjutnya dijabarkan komponen-komponen yang diperlukan dan dipilih untuk menjalankan sistem tersebut. Peletakkan komponen disesuaikan agar titik beratnya maksimal selisih $0.5 \%$ dari longitudinal center of buoyancy (LCB) dari model kapal yang bernilai $45.9 \mathrm{~cm}$. Gambaran dari peletakkan komponen sistem yang ada di model kapal tertuang pada Gambar 2.

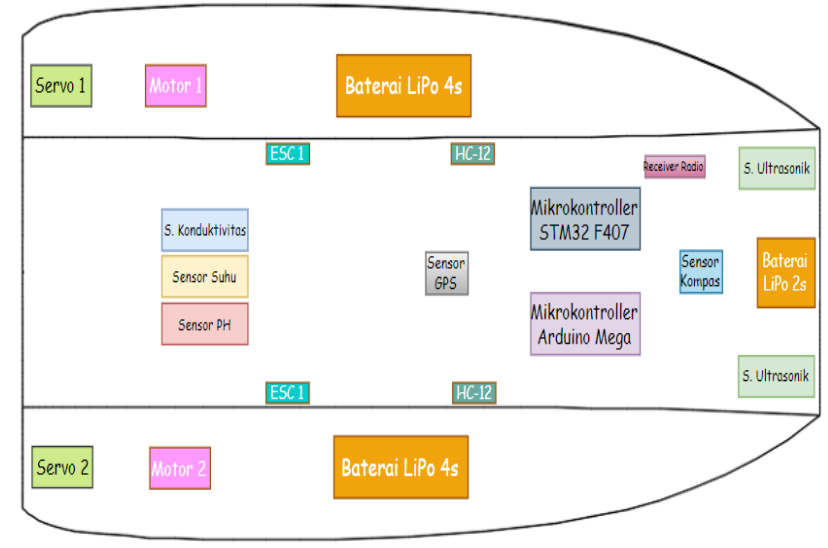

Gambar 2. Layout komponen dari sistem pada model kapal.

\section{B. Diagram Blok Sistem}

Diagram blok sistem merupakan diagram dari sebuah sistem, yang bagian utama atau fungsi yang diwakili oleh blok dan dihubungkan dengan garis yang menunjukkan hubungan dari blok.

Berdasarkan Gambar 3, sistem pada model kapal tanpa awak dibagi menjadi 3 bagian. Bagian pertama adalah sistem propulsi, yaitu sistem yang mengatur penggerak dan kemudi kapal. Bagian kedua adalah sistem autopilot, yaitu sistem yang mengatur navigasi autopilot dan menghindari halangan pada model kapal tanpa awak. Bagian ketiga adalah sistem akusisi data sensor, yaitu sistem yang mengatur akusisi data dari sensor untuk mendeteksi tingkat kualitas air.

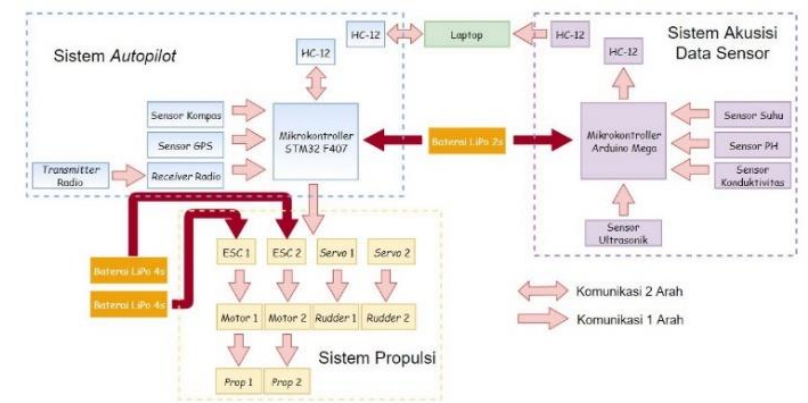

Gambar 3. Diagram blok system.

\section{Sistem Propulsi}

Berikut adalah diagram blok desain sistem propulsi untuk model kapal tanpa awak yang ditunjukkan pada Gambar 4.

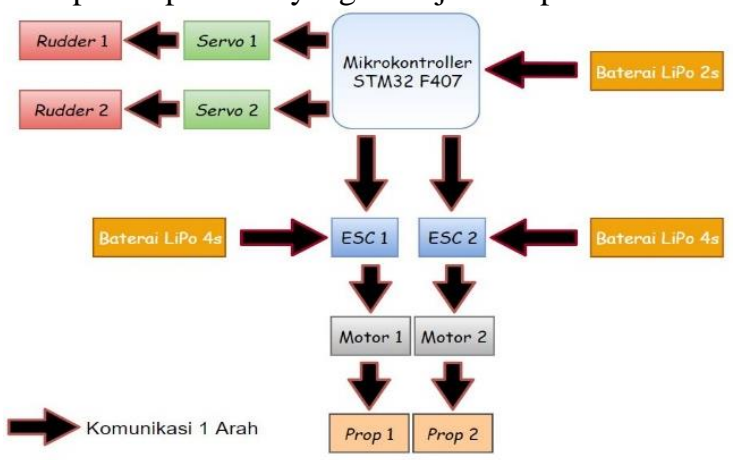

Gambar 4. Diagram blok sistem propulsi.

\section{Sistem Autopilot}

Berikut adalah diagram blok desain sistem autopilot untuk model kapal tanpa awak yang ditunjukkan pada Gambar 5.

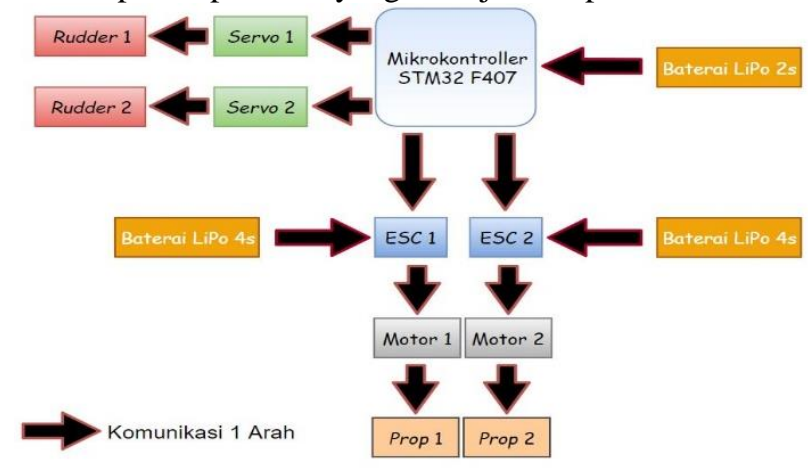

Gambar 5. Diagram blok sistem autopilot.

Algoritma dalam sistem autopilot adalah navigasi waypoint antara dua titik koordinat. Dari kedua titik tersebut dapat diketahui arah dan jaraknya. Nilai tersebut akan dijadikan parameter beserta arah heading real dari model kapal untuk dikontrol dengan metode PID. Kontrol tersebut akan mengarahkan model kapal ke titik tujuan dengan memanipulasi rudder agar selalu mengarah ke titik tujuan.

\section{E. Sistem Akusisi Data Sensor}

Berikut adalah diagram blok desain sistem akusisi data sensor untuk model kapal tanpa awak yang ditunjukkan pada Gambar 6.

\section{PENGUJIAN DAN ANALISIS}

Pada penelitian ini, model kapal tanpa awak diimplementasikan sebagai media survei tingkat kualitas air. 
Selain itu, model kapal dapat bergerak dalam mode autopilot sehingga model kapal dapat secara otomatis begerak ke daerah tujuan pengecekkan kualitas air sesuai perintah user. User dapat memantau pergerakan model kapal melalu GPS yang ditampilkan di program Graphic User Interface (GUI). Oleh karena itu, dibuatlah sebuah sistem yang memungkinkan kapal untuk bergerak secara autopilot dengan menggunakan sistem navigasi GPS dan kompas yang menggunakan algoritma waypoint. Jadi, model kapal dapat bergerak secara autopilot yang dikendalikan oleh laptop di Control Ground Station dengan interface GUI dimana komunikasinya menggunakan modul wireless, tanpa sepenuhnya menggunakan remote control dan bisa mengikuti jalur yang telah dibuat dengan bantuan perangkat sensor GPS dan dipandu sensor kompas yang telah terintegrasi dalam sistem autopilot model kapal. Hasil pengolahan dari sistem tersebut akan dikirimkan secara wireless dari laptop dan diterima oleh sistem propulsi sehingga model kapal dapat bergerak dan bermanuver sesuai kontrol yang dilakukan saat mode autopilot. Model kapal juga memiliki sensor ultrasonik yang menjadi sensor jarak untuk menghindari halangan yang ada di depan model kapal. Sehingga, ketika model kapal melakukan navigasi secara autopilot, model kapal tidak akan menabrak halangan yang menghalanginya.

Pada tahap awal, user akan membuat titik-titik waypoint sebagai daerah survei untuk diketahui tingkat kualitas airnya. Setelah itu, user akan menjalankan mode autopilot dan model kapal akan bergerak mengikuti waypoint yang sudah ditentukan. Secara otomatis, model kapal akan menghindari halangan-halangan yang ada di depannya sehingga tabrakan tidak akan terjadi. Ketika model ini sampai pada titik-titik waypoint tertentu, model kapal akan secara otomatis menghentikan putaran mesin selama 5 detik untuk menstabilkan pembacaan sensor yang berkaitan dengan kualitas air. Nilai pembacaan data kualitas air juga ditampilkan dalam GUI pada laptop di Control Ground Station yang dapat dilihat secara langsung oleh user.

\section{A. Pengujian Sistem Propulsi}

Pengujian sistem propulsi adalah pengujian yang dilakukan untuk mengetahui fungsional sistem propulsi yang terdapat pada model kapal tanpa awak. Pengujian sistem propulsi model kapal dilakukan komponen sistem propulsi sudah dipasang pada model kapal. Pengujian yang dilakukan yaitu uji fungsi pengendalian mode manual, fungsi motor, rudder, propeller, dan pengujian kecepatan pada model kapal. Seperti yang ditunjukkan pada Gambar 7.

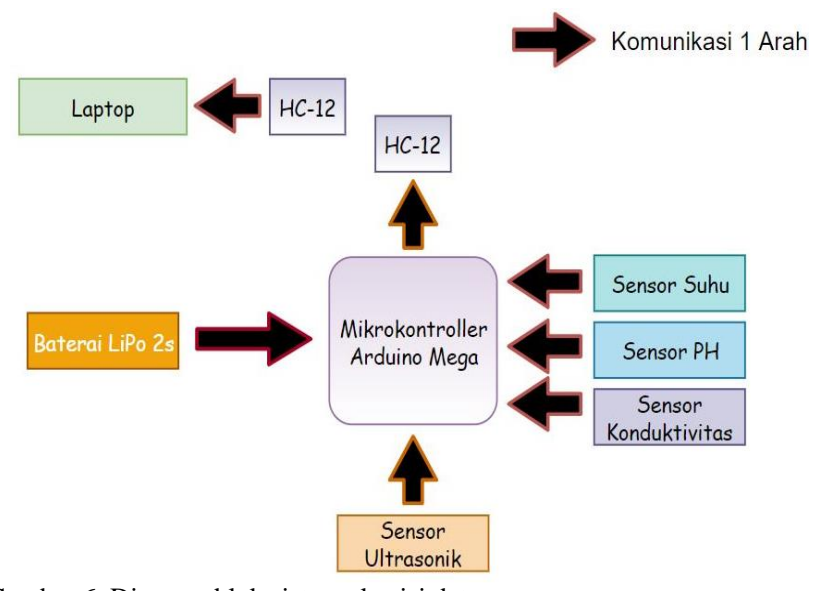

Gambar 6. Diagram blok sistem akusisi data sensor.

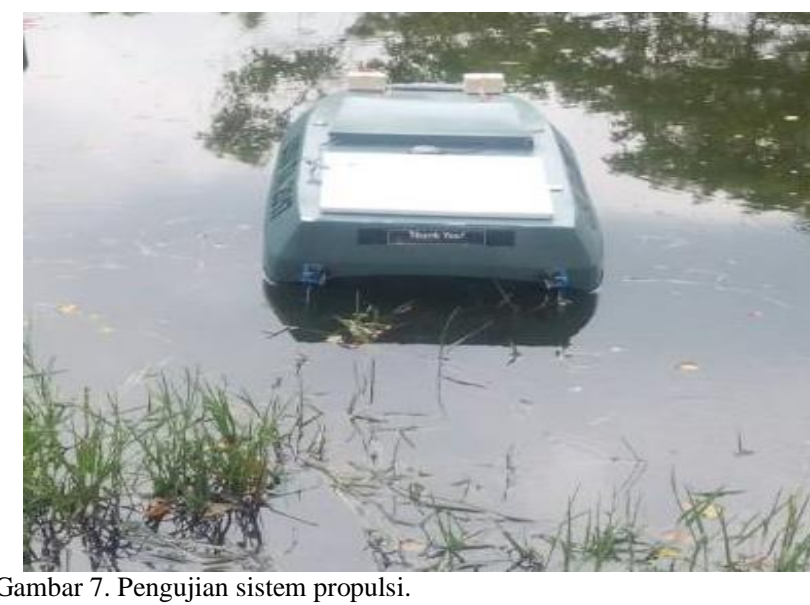

Berikut merupakan hasil pengujian sistem propulsi yang ditunjukkan pada Tabel 1 .

Tabel 1.

Hasil pengujian sistem propulsi

\begin{tabular}{|c|c|c|c|}
\hline No. & Parameter Pengujian & Hasil & Keterangan \\
\hline 1 & $\begin{array}{l}\text { Fungsi pengendailan } \\
\text { mode manual }\end{array}$ & Baik & $\begin{array}{l}\text { Pengendalian mode manual dapat } \\
\text { dilakukan dengan baik }\end{array}$ \\
\hline 2 & $\begin{array}{l}\text { Fungsi } \\
\text { brushless }\end{array}$ & Baik & $\begin{array}{l}\text { Motor brushless dapat bekerja } \\
\text { dengan baik }\end{array}$ \\
\hline 3 & Fungsi rudder & Baik & Rudder dapat bekerja dengan baik \\
\hline 4 & Fungsi propeller & Baik & $\begin{array}{l}\text { Propeller dapat bekerja dengan } \\
\text { baik }\end{array}$ \\
\hline 5 & Pengujian kecepatan & Baik & $\begin{array}{l}\text { Kecepatan maksimal mencapai } \\
4.06 \mathrm{~m} / \mathrm{s} \text { atau } 7.892 \mathrm{knot}\end{array}$ \\
\hline
\end{tabular}

\section{B. Pengujian Konektivitas GUI dengan Sistem Autopilot}

Pengujian ini dilakukan untuk mengetahui konektivitas dan fungsionalitas dari GUI yang telah dibuat sebelumnya dan akses ke mikrokontroler yang ada di model kapal Sehingga, dapat dipastikan bahwa seluruh sistem yang ada pada model kapal dan Control Ground Station telah terkoneksi dengan baik. Seperti yang ditunjukkan pada Gambar 8.

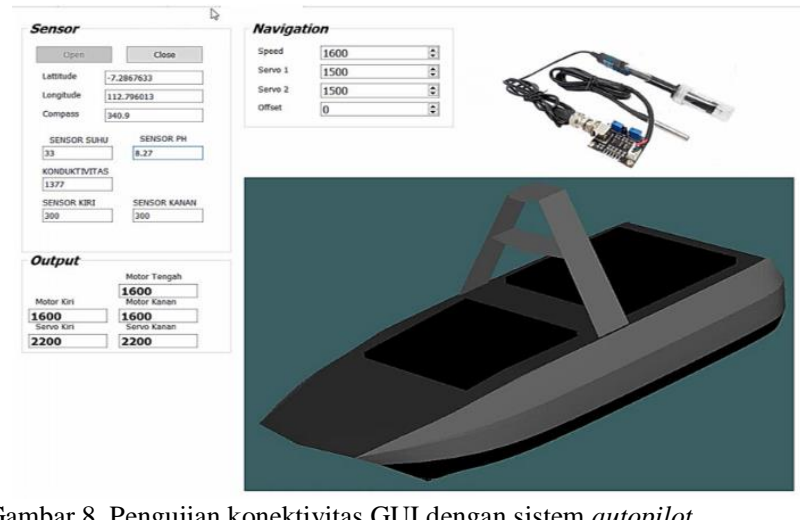

Berikut merupakan hasil pengujian yang ditunjukkan pada Tabel 2.

Tabel 2.

Hasil pengujian konektivitas GUI dengan sistem autopilot

\begin{tabular}{clcccc}
\hline \hline No. & Pengujian & $\begin{array}{c}\text { Banyak } \\
\text { Pengujian }\end{array}$ & Berhasil & Gagal & Hasil \\
\hline 1 & $\begin{array}{l}\text { Mengakses } \\
\text { GUI }\end{array}$ & 20 & 18 & 2 & Berhasil \\
2 & $\begin{array}{l}\text { Komunikasi } \\
\text { antar kedua } \\
\text { perangkat }\end{array}$ & 20 & 16 & 4 & Berhasil \\
\hline \hline
\end{tabular}

C. Pengujian Sistem Kontrol Navigasi Autopilot

Pengujian ini dilakukan untuk mengetahui fungsionalitas dari sensor GPS dan kompas, ESC, motor brushless, dan 
motor servo untuk rudder saat model kapal bernavigasi secara autopilot sesuai lintasan yang ditentukan pada Gambar 9.

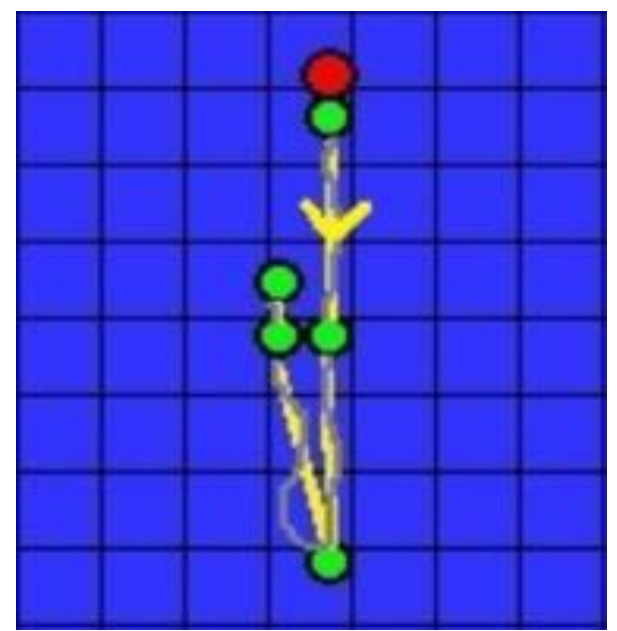

Gambar 9. Pengujian sistem kontrol navigasi autopilot di salah satu lintasan.

Berikut merupakan hasil pengujian yang ditunjukkan pada Tabel 3.

Tabel 3.

Hasil pengujian sistem kontrol navigasi autopilot

\begin{tabular}{cccl}
\hline \hline No. & Pengujian & Hasil & \multicolumn{2}{c}{ Keterangan } \\
\hline 1 & Lintasan 1 & Baik & $\begin{array}{l}\text { Tepat menuju waypoint, tetapi lintasan yang } \\
\text { ditempuh tidak sesuai lintasan yang } \\
\text { diinginkan } \\
\text { Tepat menuju waypoint, tetapi lintasan yang } \\
\text { ditempuh tidak sesuai lintasan yang } \\
\text { diinginkan } \\
\text { Tepat menuju waypoint, tetapi lintasan yang } \\
\text { ditempuh tidak sesuai lintasan yang } \\
\text { diinginkan } \\
\text { Tepat menuju waypoint, tetapi lintasan yang } \\
\text { ditempuh tidak sesuai lintasan yang } \\
\text { diinginkan }\end{array}$ \\
Lintasan 3 & Bain & Baik \\
\hline \hline
\end{tabular}

D. Pengujian Konsistensi Sistem Kontrol Navigasi Autopilot

Pengujian ini dilakukan untuk mengetahui konsistensi dan kestabilan sistem kontrol navigasi autopilot. Pengujian pada sistem kontrol ini dilakukan 5 kali dengan kecepatan dan displacement yang sama. Berikut merupakan hasil pengujian yang ditunjukkan pada Gambar 10 yang menunjukkan bahwa lintasan dari model kapal konsisten saat pengujian meskipun tidak $100 \%$ sama.

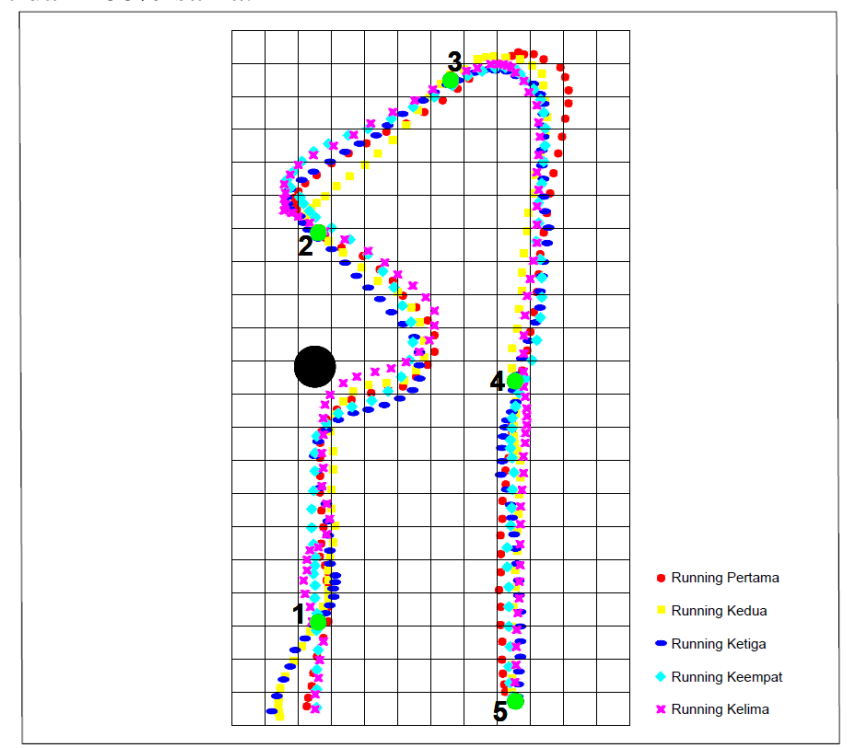

Gambar 10. Lintasan 5 kali pengujian sistem kontrol navigasi autopilot.

\section{E. Pengujian Sistem Kontrol Menghindari Halangan}

Pengujian ini dilakukan untuk mengetahui respon dari kontrol menghindar dari objek halangan di depan model kapal. Dari pengujian yang dilakukan, didapatkan bahwa respon menghindar akan menjadi lebih lambat (lebih dekat dengan objek halangan) ketika dilakukan pada kecepatan yang lebih tinggi maupun displacement yang lebih tinggi. Seperti yang ditunjukkan pada Gambar 11 .

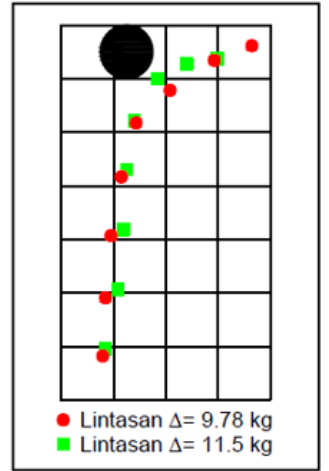

Gambar 11. Lintasan menghindar dengan displacement 9.78 dan $11.5 \mathrm{~kg}$.

\section{F. Pengujian Fungsi Sensor PH}

Pengujian ini dilakukan untuk mengetahui kerja dan fungsionalitas dari sensor PH. Pengujian dilakukan di Danau 8 ITS, dengan daerah sampel adalah 5 titik waypoint yang sebelumnya sudah di-setting sesuai kehendak user melalui sistem autopilot. Berikut merupakan hasil pengujian sensor PH yang ditunjukkan pada Tabel 4.

Tabel 4.

Hasil pengujian sensor $\mathrm{PH}$

\begin{tabular}{cccc}
\hline \hline Lokasi (WP*) & Sensor PH & PH Meter & Error \\
\hline 1 & 8.35 & 8.25 & $1.2 \%$ \\
2 & 8.45 & 8.21 & $2.9 \%$ \\
3 & 8.43 & 8.20 & $2.8 \%$ \\
4 & 8.32 & 8.16 & $2.0 \%$ \\
5 & 8.38 & 8.17 & $2.6 \%$ \\
\hline \hline
\end{tabular}

${ }^{\mathrm{a} W P}$ - Waypoint.

Error dari hasil pengujian sensor $\mathrm{PH}$ berada pada rentang $1.2-2.9 \%$.

\section{G. Pengujian Fungsi Sensor Konduktivitas}

Pengujian ini dilakukan untuk mengetahui kerja dan fungsionalitas dari sensor konduktivitas. Pengujian dilakukan di Danau 8 ITS, dengan daerah sampel adalah 5 titik waypoint yang sebelumnya sudah di-setting sesuai kehendak user melalui sistem autopilot. Berikut merupakan hasil pengujian sensor konduktivitas yang ditunjukkan pada Tabel 5 .

Tabel 5.

Hasil pengujian sensor konduktivitas

\begin{tabular}{cccc}
\hline \hline Lokasi (WP*) & Sensor $(\mathrm{uS} / \mathrm{cm})$ & Pembanding $(\mathrm{uS} / \mathrm{cm})$ & Error \\
\hline 1 & 7084 & 6834 & $3.7 \%$ \\
2 & 6536 & 6504 & $0.5 \%$ \\
3 & 6842 & 6504 & $5.2 \%$ \\
4 & 6882 & 6834 & $0.7 \%$ \\
5 & 6848 & 6834 & $0.2 \%$ \\
\hline \hline aWP - Waypoint & &
\end{tabular}

Error dari hasil pengujian sensor konduktivitas berada pada rentang $0.2-5.2 \%$.

\section{H. Pengujian Fungsi Sensor Suhu}

Pengujian ini dilakukan untuk mengetahui kerja dan fungsionalitas dari sensor suhu. Pengujian dilakukan di Danau 8 ITS, dengan daerah sampel adalah 5 titik waypoint yang sebelumnya sudah di-setting sesuai kehendak user 
melalui sistem autopilot. Berikut merupakan hasil pengujian sensor suhu yang ditunjukkan pada Tabel 6 .

Tabel 6.

Hasil pengujian sensor suhu

\begin{tabular}{cccc}
\hline \hline Lokasi $\left(\mathrm{WP}^{*}\right)$ & Sensor $\left({ }^{\mathrm{O}} \mathrm{C}\right)$ & Pembanding $\left({ }^{\mathrm{O}} \mathrm{C}\right)$ & Error \\
\hline 1 & 33.31 & 33.20 & $0.3 \%$ \\
2 & 32.88 & 33.20 & $1.0 \%$ \\
3 & 32.88 & 33.20 & $1.0 \%$ \\
4 & 33.00 & 32.20 & $2.5 \%$ \\
5 & 33.19 & 32.20 & $3.1 \%$ \\
\hline \hline
\end{tabular}

${ }^{\mathrm{a}} \mathrm{WP}$ - Waypoint.

Error dari hasil pengujian sensor suhu berada pada rentang $0.3-3.1 \%$

\section{KESIMPULAN/RINGKASAN}

1. Didapatkan general arrangement baru menyesuaikan kebutuhan sistem yang ada di dalam model kapal.

2. Didapatkan desain sistem propulsi dan pembuatan sistem propulsi pada model kapal.

3. Didapatkan desain sistem autopilot dan pembuatan sistem autopilot pada model kapal.

4. Didapatkan desain sistem akusisi data sensor dan pembuatan sistem akusisi data sensor pada model kapal.

5. Hasil pengujian untuk sistem propulsi didapat bahwa pengendalian fungsi mode manual, motor brushless, rudder, dan propeller dapat bekerja dengan baik. Pada pengujian kecepatan, untuk kecepatan maksimal yang dapat dicapai adalah $4.06 \mathrm{~m} / \mathrm{s}$ atau 7.892 knot.

6. Hasil pengujian untuk sistem autopilot didapat bahwa running GUI dan konektivitas GUI dengan sistem yang ada di model kapal dinyatakan berhasil. Pengujian dilakukan sebanyak 20 kali dengan masing-masing tingkat berhasil mencapai 18 dan 16 kali, sementara tingkat kegagalan mencapai 2 dan 4 kali. Pengujian kontrol autopilot juga berhasil dilaksanakan dengan pengujian 4 lintasan berbeda dan mencapai titik-titik kordinat yang ditentukan meskipun lintasan yang dilalui tidak seperti lintasan yang diharapkan. Model kapal juga dapat menghindari halangan di depannya di mana dengan kenaikan kecepatan maupun displacement akan membuat respon menghindar model kapal lebih lambat, sehingga pergerakan menghindarnya lebih dekat dengan objek halangan.

7. Hasil pengujian untuk sistem akusisi data sensor dinyatakan berhasil. Dari hasil pengujian didapatkan bahwa error dari masing-masing sensor $\mathrm{PH}$, konduktivitas, dan suhu dibandingkan dengan alat ukurnya masing-masing adalah $1.2-2.9 \%, 0.2-5.2 \%$, dan $0.3-3.1 \%$.

\section{DAFTAR PUSTAKA}

[1] S. Sugita and E. Damaranda, "Pembuatan purwarupa tes model untuk menguji sistem autopilot pada unmanned surface vehicle (USV)," ITS Surabaya, 2017

[2] A. W. Browning, "A mathematical model to simulate small boat behaviour," Bournemouth Polytechnic, 1990.

[3] C. Lim, "Autopilot design for ship control," Loughborough University of Technology, 1980.

[4] S. R. M. Jerry Jeliandra Suja, Sulistiyanti and M. Komarudin, "Sistem Navigasi pada Unmanned Surface Vehicle untuk Pemantauan Daerah Perairan,"J. Rekayasa dan Teknol. Elektro, vol. 34, 2017.

[5] D. Hardianto, "Pembuatan Konsep Desain Unmanned Surface Vehicle (USV) untuk Monitoring Wilayah Perairan Indonesia," Publ. Ilm. Online Mhs. ITS, vol. 6, no. 2, 2017.

[6] F. Ramadhan and W. D. Aryawan, "Pembuatan detail Desain unmanned surface vehicle (USV) untuk monitoring wilayah perairan indonesia," $J$. Tek. ITS, vol. 6, no. 2, 2017. 